\title{
COVID-19 and the second wave during autumn: preventive strategies in cardiac and thoracic surgery divisions
}

\author{
Francesco Donatelli (D) Antonio Miceli · Silvia Cirri · Enrico Coscioni · Claudio Napoli (D)
}

Received: 9 November 2020 / Accepted: 12 November 2020 / Published online: 10 December 2020 (C) Springer-Verlag GmbH Austria, part of Springer Nature 2020

Dear Editor,

During the current second peak of the COVID-19 (coronavirus disease 2019) pandemic seen worldwide, increasing critical care unit bed capacity, associated with an increase in both ECMO (extracorporeal membrane oxygenation) and mechanical ventilation devices, is crucial for maintaining an adequate setting for cardiothoracic surgery in referral centers [1]. Theoretically, this urgency will persist until herd immunity is acquired either by natural infection or through vaccination, which has a low probability of being available on a global scale by the 2020 fall and winter seasons. Results of three early-phase COVID-19 vaccine trials were reported, one from the mRNA-1273 Study Group, the second from the Jenner Institute at Oxford University with support from AstraZeneca, and the third from CanSino Biologics in Wuhan, China [2-4]. These ongoing clinical trials have reported promising data by inducing an antiSARS-CoV-2 (severe acute respiratory syndrome coronavirus 2) humoral response.

F. Donatelli, MD · A. Miceli, MD, PhD · S. Cirri, MD Chair of Cardiac Surgery, Department of Cardiothoracic Center, Istituto Clinico Sant'Ambrogio, University of Milan, Milan, Italy

\section{E. Coscioni, MD}

Department of Cardiac Surgery, Azienda Ospedaliera Universitaria San Giovanni di Dio e Ruggi d'Aragona, Salerno, Italy

Prof. C. Napoli, MD, PhD (ه)

Clinical Department of Internal Medicine and Specialistics, Azienda Ospedaliera Universitaria, and University Department of Advanced Medical and Surgical Sciences, University of Campania “Luigi Vanvitelli”, Naples, Italy claudio.napoli@unicampania.it
However, additional mitigation methods are needed. Additionally, cocirculation of COVID-19 and the seasonal influenza virus has been established [5]; thus, we are observing the condition that influenza per $s e$ exerts pressure on health care systems through increasing hospital admissions to critical units, accounting for increasing mortality worldwide. Recently, it was established that viral respiratory infections may act through synergic epigenetic mechanisms in the development of severe forms of respiratory infections [6]. Moreover, gram-positive pathogens, Staphylococcus aureus, group A Streptococcus, and Streptococcus pneumoniae have been shown to co-isolate with COVID-19 [7]. Therefore, it was proposed that pneumococcal vaccination could prevent superimposed S. pneumoniae infection in patients with COVID-19. As the infection rate for COVID-19 has been surprisingly high worldwide since mid-September 2020, it is mandatory to follow tight infection control measures including applying bundles in ventilator-associated pneumonia and central line-associated bloodstream infections [8, 9]. This to assure both the ordinary and urgent waiting lists for cardiac and thoracic surgery patients. Infection prevention and antibiotic stewardship would limit the spread of multidrug-resistant (MDR) organisms [10]. It is noteworthy that also MDR organisms may exert their detrimental action through epigenetic mechanisms [11]. Thus, one of the novel challenges is to control such epigenetic mechanisms in addition to current validated therapies against COVID-19 [6].

The second wave is the time when the implementation of infection control is required in the preparation of surgical interventions, also in patients with a previous history of COVID-19 [12]. We need to depict a new scenario for these frailty patients in "phase 3" of the pandemic $[1,12]$. This clinical setting needs to pay particular attention to cardiovascular involvement 


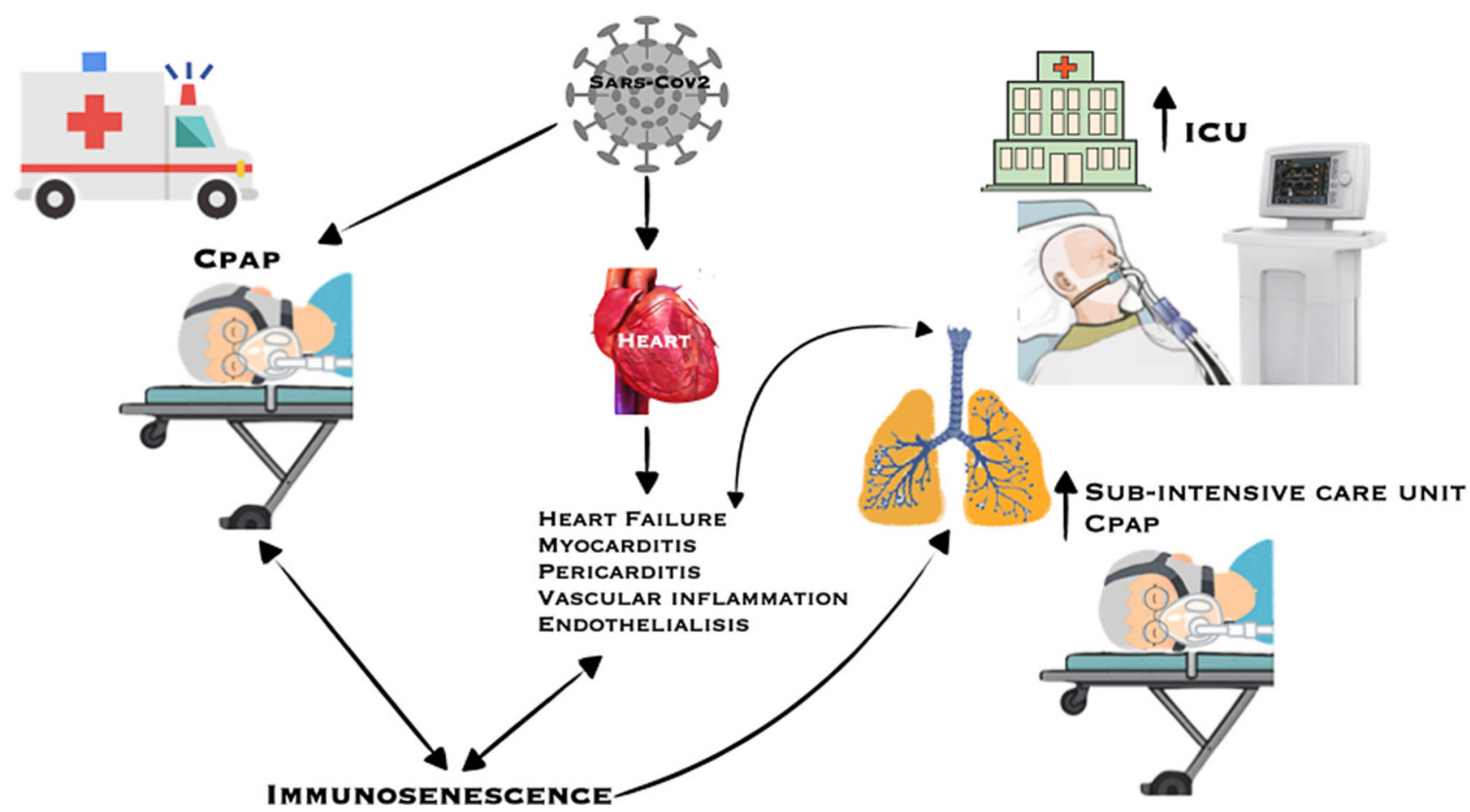

Fig. 1 Clinical scenario in which elderly subjects have more possibilities to require intensive care unit (ICU) assistance. This is partially due to immunosenescence and car- diac susceptibility to COVID-19 (Corona Virus disease 2019). $C P A P$ continuous positive airway pressure and immunosenescence in elderly patients [13-15], who have more possibilities to require ventilatory support when hospitalization is required for COVID-19 (Fig. 1). Thus, the second wave that we are suffering needs to be adressed by a multidisciplinary team supporting cardiac and thoracic surgery units that include experts in vaccines, geriatrics, pneumology, and virology as well as dedicated rehabilitation programs for these frailty patients after surgery.

Conflict of interest F. Donatelli. A. Miceli, S. Cirri, E. Coscioni, and C. Napoli decalre that they have no no competinginterests.

\section{References}

1. Donatelli F, Miceli A, Glauber M, Cirri S, Maiello C, Coscioni E, et al. Adult cardiovascular surgery and the coronavirus disease 2019 (COVID-19) pandemic: the Italian experience. Interact CardioVasc ThoracSurg. 2020; https:/ / doi.org/10.1093/icvts/ivaa186.

2. Jackson LA, Anderson EJ, Rouphael NG, Roberts PC, Makhene M, Coler RN, et al. An mRNA Vaccine against SARS-CoV-2-Preliminary Report. N Engl J Med. 2020; https://doi.org/10.1056/NEJMoa2022483.

3. Folegatti PM, Ewer KJ, Aley PK, Angus B, Becker S, BelijRammerstorfer S, et al. Safety and immunogenicity of the ChAdOx1 nCoV19 vaccine against SARS-CoV-2: a preliminary report of a phase $1 / 2$, single-blind, randomised controlled trial. Lancet. 2020;396(10249):467-78. https:// doi.org/10.1016/S0140-6736(20)31604-4.

4. Lurie N, Saville M, Hatchett R, Halton J. Developing Covid-19 vaccines at pandemic speed. N Engl
J Med. 2020;382:1969-73. https://doi.org/10.1056/ NEJMp2005630.

5. Kim D, Quinn J, Pinsky B, Shah NH, Brown I. Rates of Co-infection Between SARS-CoV-2 and Other Respiratory Pathogens. JAMA. 2020;323:2085-6. https://doi.org/10. 1001/jama.2020.6266.

6. Crimi E, Benincasa G, Figueroa-Marrero N, Galdiero M, Napoli C. Epigenetic susceptibility to severe respiratory viral infections: pathogenic and therapeutic implications: a narrative review. Br J Anaesth. 2020;125(6):1002-17. https://doi.org/10.1016/j.bja.2020.06.060.

7. Hendaus MA, Jomha FA. Covid-19 induced superimposed bacterial Infection. J Biomol Struct Dyn. 2020; https:/ / doi. org/10.1080/07391102.2020.1772110.

8. Tang HJ, Chao CM, Leung PO, Lai CC. Achieving "zero" CLABSI and VAP after sequential implementation of central line bundle and ventilator bundle. Infect Control Hosp Epidemiol. 2015;36(3):365-6. https://doi.org/10.1017/ice. 2014.56.

9. McAlearney AS, Gaughan AA, DePuccio MJ, MacEwan SR, Hebert C, Walker DM. Management practices for leaders to promote infection prevention: lessons from a qualitative study. Am J Infect Control. 2020; https://doi.org/10.1016/j. ajic.2020.09.001.

10. Getahun H, Smith I, Trivedi K, Paulin S, Balkhy H. Tackling antimicrobial resistance in the COVID-19 pandemic. Bull World Health Organ. 2020;98:442-442A. https://doi.org/ 10.2471/BLT.20.268573.

11. Crimi E, Benincasa G, Cirri S, Mutesi R, Faenza M, Napoli C. Clinical epigenetics and multidrug-resistant bacterial infections: host remodelling in critical illness. Epigenetics. 2020;15:1021-34. https://doi.org/10.1080/15592294.2020. 1748918.

12. Miceli A, Donatelli F, Glauber M, Napoli C. Commentary: urgent need for careful holistic assessment post COVID-19 
hospitalization: crisis after crisis? J Thorac Cardiovasc Surg. 2020; https://doi.org/10.1016/j.jtcvs.2020.10.081.

13. Mansueto G, Niola M, Napoli C. Can COVID 2019 induce a specific cardiovascular damage or it exacerbates pre-existing cardiovascular diseases? Pathol Res Pract. 2020;216:153086. https://doi.org/10.1016/j.prp.2020. 153086.

14. Napoli C, Tritto I, Benincasa G, Mansueto G, Ambrosio G. Cardiovascular involvement during COVID-19 and clinical implications in elderly patients. A review. Ann Med Surg.
2020;57:236-43. https://doi.org/10.1016/j.amsu.2020.07. 054.

15. Napoli C, Tritto I, Mansueto G, Coscioni E, Ambrosio G. Immunosenescence exacerbates the COVID-19. Arch Gerontol Geriatr. 2020;90:104174. https://doi.org/10.1016/j. archger.2020.104174.

Publisher's Note Springer Nature remains neutral with regard to jurisdictional claims in published maps and institutional affiliations. 